\title{
石炭熱分解時のガス発生挙動に対する 昇温速度及び炭種の影響
}

宝田 恭之*・後藤 信義*・森下 佳代子*・林 浩司*・片平 英裕*2 ・高橋 博*3

Effects of Heating Rate and Coal Type on Gas Evolution during Coal Pyrolysis

Takayuki Takarada, Nobuyoshi Goto, Kayoko Morishita, Koji Hayashi, Hidehiro Katahira and Hiroshi Takahashi

Synopsis : In order to get a decisive conclusion on the effect of the heating rate on gas evolution behaviour during coal pyrolysis, the pyrolysis of coal was systematically investigated in thermo-balance using six coals which have different carbon contents ranging from 81 to 88 (wt $\%$, daf). The heating rate was ranged from $3^{\circ} \mathrm{C} / \mathrm{min}$ to $300^{\circ} \mathrm{C} / \mathrm{min}$. The evolution rates of $\mathrm{CH}_{4}, \mathrm{C}_{2} \mathrm{H}_{4}, \mathrm{C}_{2} \mathrm{H}_{6}, \mathrm{H}_{2}, \mathrm{CO}$ and $\mathrm{CO}_{2}$ were measured. As the heating rate increased, the maximum weight decrease rate and the maximum gas evolution rate were shifted to higher temperatures. The gas and coke yields were decreased and the liquid yield was increased with an increase in the heating rate.

Six coals were heated at constant temperatures ranging from $360^{\circ} \mathrm{C}$ to $500^{\circ} \mathrm{C}$ for $180 \mathrm{~min}$. The ultimate volatile matter content at each holding temperature was decided. It was found that the ultimate volatile matter content depended on the coal rank at lower temperatures and a large amount of gas was evolved from low rank coals at a temperature as low as $400^{\circ} \mathrm{C}$.

Key word : pyrolysis; heating rate ; coal type ; gas evolution.

\section{1. 緒言}

石炭加熱時の軟化溶融膨張挙動は石炭の熱分解過程を反 映した結果であり，熱分解時のガス発生挙動と密接な関係 にある。石炭を乾留する際の軟化溶融膨張挙動をより正確 に把握するためには熱分解挙動に対する熱分解条件及び炭 種の影響を検討し、熱分解時のガス発生挙動を明らかにす ることが重要である。石炭のコークス化に伴うガス発生挙 動に関しては古くから多くの研究がなされている自が゙，熱 分解条件の範囲が狭い，使用炭種が限られているなど断片 的なデータが多い。高効率なコークス製造には，より広い 熱分解条件と幅広い炭化度の石炭との組み合わせによる系
統的な基礎研究が必要不可欠である。本研究では, 熱分解 時のガス発生挙動に対する熱分解条件及び炭種の影響を検 討するため， 6 種類の石炭を用いて種々の昇温形式で熱分 解を行い, 熱分解プロファイルおよび発生プロファイルを 検討した。特に，石炭の熱分解開始温度付近でのガス発生 が重要であると考え，360 500 ${ }^{\circ} \mathrm{C}$ 温度域で一定温度熱分 解を行い, ガス発生挙動を詳細に調べた。

\section{2. 実験}

\section{$2 \cdot 1$ 試料}

炭素含有量の異なる 6 種類の石炭を粉砕, フルイ分けし,

Table 1. Analyses of Coal.

\begin{tabular}{|c|c|c|c|c|c|c|c|c|c|c|}
\hline & & $\begin{array}{r}P \\
\text { analy }\end{array}$ & $\begin{array}{l}\text { xima } \\
\text { is(wt) }\end{array}$ & dry) & & Uitim & $\begin{array}{l}\text { te ar } \\
t \%, d\end{array}$ & $\begin{array}{l}\text { alysis } \\
\text { ) }\end{array}$ & & CSN \\
\hline & & Ash & VM & FC & C & $\mathrm{H}$ & $\mathbf{N}$ & $\mathrm{s}$ & 0 & \\
\hline Lusca & (Lu) & 9.5 & 23.5 & 67.0 & 88.3 & 4.6 & 1.5 & 0.3 & 5.3 & 7.0 \\
\hline Goonyella & (Go) & 9.8 & 23.4 & 66.8 & 88.1 & 5.1 & 1.9 & 0.6 & 4.4 & 7.5 \\
\hline Pittstone-M & $(\mathrm{Pi})$ & 7.3 & 34.3 & 58.4 & 85.7 & 5.5 & 1.6 & NA & NA & 7.0 \\
\hline Workworth & (Wo) & 13.8 & 34.2 & 52.0 & 84.7 & 5.9 & 1.8 & 0.6 & 7.0 & 6.0 \\
\hline Witbank & $(W i)$ & 8.0 & 32.9 & 59.1 & 82.7 & 4.5 & 2.2 & 0.6 & 10.0 & 2.0 \\
\hline K-prima & (Kp) & 3.8 & 43.4 & 52.8 & 81.2 & 5.9 & 1.3 & 0.4 & 11.2 & 2.0 \\
\hline
\end{tabular}

平成 7 年11月 1 日受付 平成 8 年 1 月18日受理（Received on Nov. 1 1995; Accepted on Jan. 18, 1996)

* 群馬大学工学部 (Faculty of Engineering, Gunma University, 1-5-1 Tenjin-cho Kiryu 376)

* 2 新日鐵化学 (株)君津製造所 (Kimitsu Works, Nippon Steel Chemical Co., Ltd.)

*3 三菱化学(株)生産技術センター (Technology and Engineering Center, Mitsubishi Chemical Corporation) 
12〜32meshに揃えたものを用いた。分析値をTable 1 に示 寸。

\section{$2 \cdot 2$ 熱分解実験}

熱分解実験は熱天科を用いて行った。約150mgの試料を石 英セルに量りとり，純窒素気流中，種々の昇温条件で熱分 解した。熱分解実験は昇温条件によって定速昇温熱分解と 一定温度での熱分解実験の 2 種類に分けられる。定速昇温 熱分解実験は， 3 種類の昇温速度 $\left(3,30,300^{\circ} \mathrm{C} / \mathrm{min}\right)$ で $1000^{\circ} \mathrm{C}$ まで昇温して行った。一定温度熱分解実験は, 所定の 温度まで $30^{\circ} \mathrm{C} / \mathrm{min} て ゙$ 昇温し, 各温度で $180 \mathrm{~min}$ 保持し，その 後 $1000^{\circ} \mathrm{C}$ まで再び $30^{\circ} \mathrm{C} / \mathrm{min}$ で昇温することにより行った。 熱重量曲線を測定するとともに，定速昇温熱分解実験では $100^{\circ} \mathrm{C}$ 毎に, 一定温度熱分解実験では 30 分毎に生成ガスをサ ンプリングし,ガスクロマトグラフィー (GC)及びIRガス分 析計で定量分析した。測定ガスは $\mathrm{CH}_{4}, \mathrm{C}_{2} \mathrm{H}_{6}, \mathrm{C}_{2} \mathrm{H}_{4}, \mathrm{H}_{2}$, $\mathrm{CO}$ 及ご $\mathrm{CO}_{2}$ である。炭化水素ガスはFID, $\mathrm{H}_{2}$ はTCDを備え た $\mathrm{GC}$ にり測定した。比較的高濃度 (100ppm以上)のCO及 び $\mathrm{CO}_{2}$ はIRガス分析計により, また，低濃度の $\mathrm{CO}$ 及び $\mathrm{CO}_{2}$ はGCで分離後メタンコンバーターでメタン化し, FIDによ り測定した。液収率は全重量からガス重量及びューク重量 を差し引くことによって推算した。従って，この液収率に は水，軽質液状炭化水素，タールが含まれる。

\section{3. 結果および考察}

\section{$3 \cdot 1$ 定速昇温熱分解}

6 種類の石炭を用いて 3 種の昇温速度で熱分解した。熱 重量曲線の一例をFig. 1 に示す。昇温速度が大きくなるに従 って, 重量減少曲線は高温側にシフトすることが分かる。 この現象は本実験で用いた全ての石炭で認められた。最大 重量減少速度に対応する熱分解温度 (Tmax) と用いた石炭 の炭素含有量との関係をFig. 2 に示す。いずれの昇温速度に おいてもTmaxは, 炭素含有量が多くなるに連れて高くなる。 また, 昇温速度の増加に伴い,いずれの石炭においても Tmax は高くなった。昇温速度を $3^{\circ} \mathrm{C} / \mathrm{min}$ か $530^{\circ} \mathrm{C} / \mathrm{min}$ に増加す ることによって $50 \sim 70^{\circ} \mathrm{C}, 30^{\circ} \mathrm{C} / \mathrm{min}$ か $5300^{\circ} \mathrm{C} / \mathrm{min} に$ 増加す ることによって更に50〜70 $\mathrm{C}$ の温度シフトが認められた。 た，温度シフトの程度は炭種にそれほど依存しないことも 分かる。昇温速度の增加に伴い, 重量曲線が高温側にシフ トすることはこれまでにも報告がある1-4)。例えば, Krevelen ら ${ }^{2)}$ は低揮発分瀝青炭を用いて0.6 6. $6^{\circ} \mathrm{C} / \mathrm{min}$ の範囲で熱 分解を行い, 最大重量減少温度か $600^{\circ} \mathrm{C}$ 程度高温側にシフトす ること走報告している。しかしながらここれまでの研究で は昇温速度の範囲が比較的狭く，また，使用した石炭の種 類も少なかった。本研究によって幅広い炭化度の石炭に対 するより一般的な結論を導くことが出来た。

Fig. 3 にガス発生プロファイルを示す。石炭はLu炭, 昇 温速度は $30^{\circ} \mathrm{C} / \mathrm{min} て ゙$ る。ガス発生は $400^{\circ} \mathrm{C}$ 付近から認めら

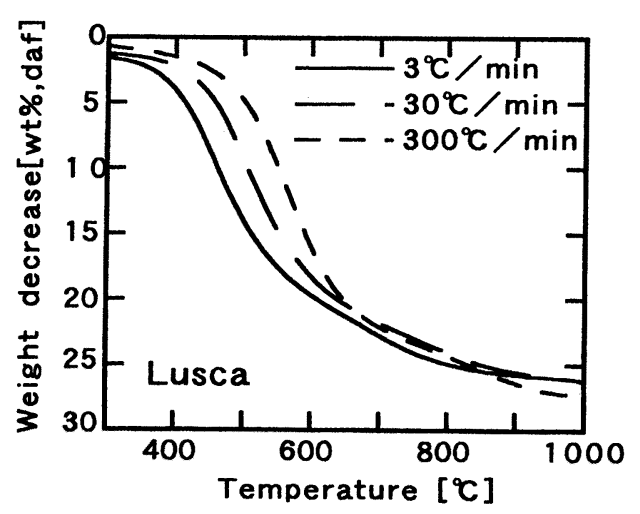

Fig. 1. TG profiles for Lu coal.

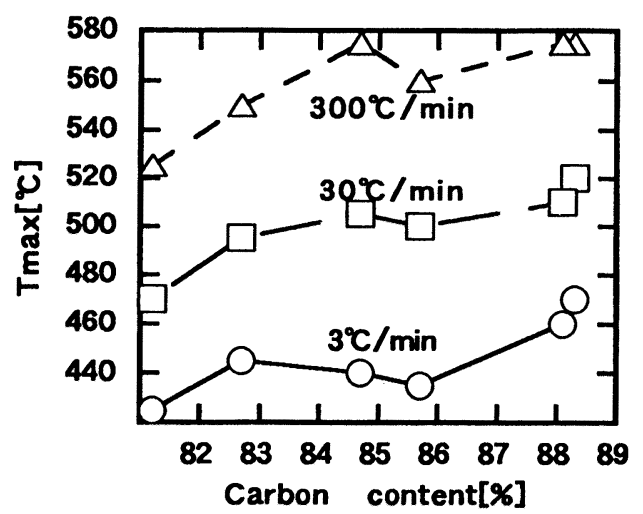

Fig. 2. Tmax vs. carbon content in raw coal.

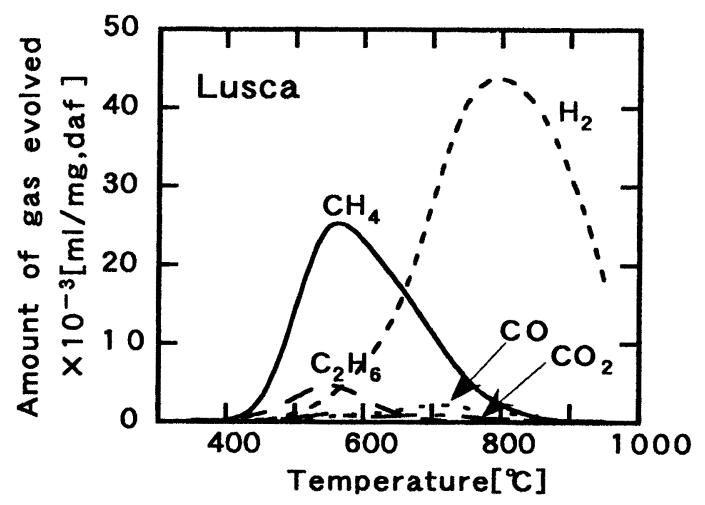

Fig. 3. Gas release profiles for Lu coal.

れ, 比較的低温域では $\mathrm{CH}_{4}, \mathrm{C}_{2} \mathrm{H}_{6}, \mathrm{CO}_{2}$ の発生が多く, 高 温域では $\mathrm{H}_{2}, \mathrm{CO}$ が生成する。他の 5 種類の石炭についても 同様の傾向が認められた。但し, 炭素含有量の低い石炭で はやや低い温度でガス発生が開始された。また，昇温速度 を増加すると, 各ガス成分の発生温度は重量減少の場合々 同様に高温側にシフトした。温度シフトは炭種にも多少依 存するが, $3{ }^{\circ} \mathrm{C} / \mathrm{min}$ から $30^{\circ} \mathrm{C} / \mathrm{min}$ へ増加によって30 40 ${ }^{\circ} \mathrm{C}$ 程度のシフトが認められた。これは, 重量隇少の時に認め られた温度シフトよりもやや少ない。これらの現象は液状 物質の生成とも関連することがらであり，今後タールを含 
めた液状物質の生成挙動に関する検討が必要である。

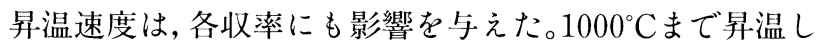
た際に得られたコーク，液，ガス収率をFig. 4 に示す。昇温 速度が大きくなると，コーク収率がやや減少し，ガス収率 も減少する。その結果として液収率が明らかに増大するこ とが分かる。石炭熱分解時の昇温速度を大きくすると液収 率が増大することはこれまでにも多くの報告があり，特に Flash pyrolysis と呼ばれる極めて昇温速度の大きな熱分解 法(例えば数干 ${ }^{\circ} \mathrm{C} / \mathrm{s}$ ) で顕著に認められている ${ }^{5,6)}$ 。低速加熱 の場合は，熱分解に伴って低分子化したガス状物質が放出 されるとともに, 結合の切断によって生成するラジカルが 石炭粒子内で再結合するためコーク収率は増加するものと 考えられる。一方，昇温速度が大きい場合は，熱分解温度 が高温側にシフトし熱分解速度が大きいため，熱分解によ って生じた比較的大きな構造単位が石炭粒子外にまで放出 され，コーク収率は減少し，液収率が増加するものと考え られる。本実験結果から, $3{ }^{\circ} \mathrm{C} / \mathrm{min}$ か $300^{\circ} \mathrm{C} / \mathrm{min}$ 程度の昇 温速度の違いでも液収率に大きな影響を与えることが分か った。また，ガス収率に対する昇温速度の影響については いくつかの断片的なデータが報告されている により，昇温速度を大きくするとガス収率が低下するとい う傾向を見いだすことが出来た。但し, 各ガス成分の収率 に対する昇温速度の影響は生成ガスの種類に依存した。 Table 2 に 3 種類の石炭について各ガス収率を示す。 $\mathrm{C}_{2} \mathrm{H}_{4}$

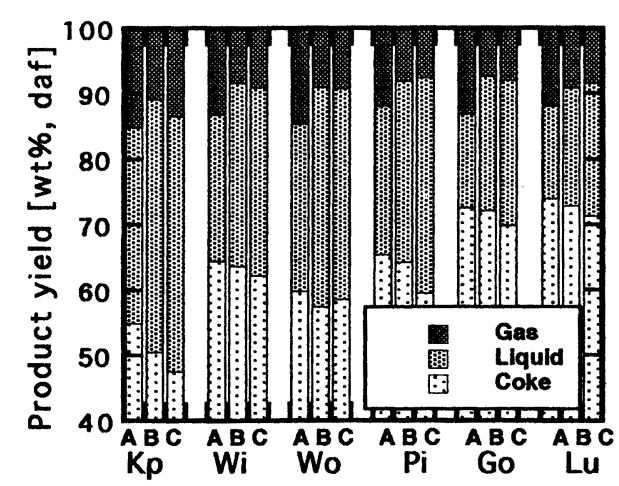

Fig. 4. Effect of heating rate on product yields. Heating rate: $\mathrm{A} ; 3^{\circ} \mathrm{C} / \mathrm{min}, \mathrm{B} ; 30^{\circ} \mathrm{C} / \mathrm{min}, \mathrm{C}$; $300^{\circ} \mathrm{C} / \mathrm{min}$.
収率は昇温速度の増加に伴い増加し，その他のガスは炭種 によって異なる部分もあるが，全体的には減少する傾向に ある。急速熱分解の実験では，熱分解温度が高くなるにつ れてオレフィン収率も高くなることが報告されている6 ${ }^{6,8)}$ これは高温域では，パラフィン類よりもオレフィン類が安 定に存在するためとされている ${ }^{8)}$ 。本実験条件下で, $\mathrm{C}_{2} \mathrm{H}_{4}$ 収 率が昇温速度の増加に伴って増加するメカニズムは明らか でないが，昇温速度の増加に伴い熱分解温度が高温側にシ フトすることが原因の一つと考えられる。

\section{$3 \cdot 2$ 一定温度熱分解}

石炭の軟化溶融現象は $350^{\circ} \mathrm{C}$ 前後から認められ，また，ガ ス発生開始温度も同様の温度域であるので，コークス化過 程を本質的に明らかにするには $400^{\circ} \mathrm{C}$ 前後の温度での熱分解 挙動が重要であると判断できる。一定温度での低温熱分解 に関しては，ほとんど報告がなく，小島ら ${ }^{9}$ が流動層を用い

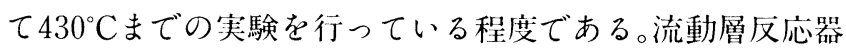
の場合，流動化粒子による二次反応の笴与走取り除くこと が比較的困難である。そこで，本研究では熱天科を用いて $360 \sim 500^{\circ} \mathrm{C}$ 温度範讲で一定温度で熱分解し重量減少速度 及びガス発生速度を測定した。3 種の石炭の重量減少プロ ファイル及び $\mathrm{CH}_{4}$ の放出速度プロファイルをFig. 5 に示す。 $\mathrm{CH}_{4}$ 発生速度は,いずれの炭種においても重量減少速度とよ く対応していることが分かる。 $\mathrm{C}_{2} \mathrm{H}_{6}, \mathrm{C}_{2} \mathrm{H}_{4}$ 及びCOの発生 速度パターンは $\mathrm{CH}_{4}$ の場合と極めて類似していた。一方, $\mathrm{CO}_{2}$ の発生速度は反応後半まで比較的大きく, $\mathrm{H}_{2}$ の発生速度は 極めて小さかった。また，いずれの石炭においても重量は 熱分解時間に伴い減少し, 180minではほぼ一定とみなせる。 重量減少率は保持温度に強く依存し，本実験により各熱分 解温度での究極揮発分量を決定することができた。各保持 温度での $180 \mathrm{~min}$ 後の揮発分量と原炭の炭素含有量との関係 をFig. 6 に示す。比較のため, 工業分析の揮発分もあわせて 示した。各保持温度での揮発分量は炭種に依存するが，炭 種による違いは低温度域で顕著に認められる。Fig. 6 に示し

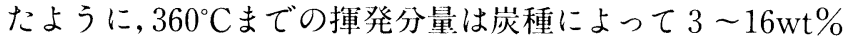
と異なるのに対し, $400 〜 450^{\circ} \mathrm{C}$ 温度範囲で放出される揮発 分量は $5 \sim 11 \mathrm{wt} \%$, 更に $450^{\circ} \mathrm{C}$ 揮発分と工業分析值(熱分 解温度 $\left.900^{\circ} \mathrm{C}\right)$ との差は $7 \sim 10 \mathrm{wt} \%$, 高い温度域ではほと

Table 2. Amount of gas evolved at various heating rate.

\begin{tabular}{|c|c|c|c|c|c|c|c|c|c|}
\hline \multirow{4}{*}{$\begin{array}{c}\text { gas } \\
\text { species }\end{array}$} & \multicolumn{9}{|c|}{ gas evolved $\left[\times 10^{-6} \mathrm{~mol} / \mathrm{g}\right.$ daf] } \\
\hline & \multicolumn{3}{|c|}{ Kp } & \multicolumn{3}{|c|}{$\mathbf{P i}$} & \multicolumn{3}{|c|}{ Lu } \\
\hline & \multicolumn{3}{|c|}{ heating rate $\left[{ }^{\circ} \mathrm{C} / \mathrm{min}\right]$} & \multicolumn{3}{|c|}{ heating rate $\left[{ }^{\circ} \mathrm{C} / \mathrm{min}\right]$} & \multicolumn{3}{|c|}{ heating rate $\left[{ }^{\circ} \mathrm{C} / \mathrm{min}\right]$} \\
\hline & 3 & 30 & 300 & 3 & 30 & 300 & 3 & 30 & 300 \\
\hline $\mathrm{CH}_{4}$ & 2114 & 1869 & 1546 & 1927 & 1654 & 1901 & 1722 & 1995 & 2288 \\
\hline $\mathrm{C}_{2} \mathrm{H}_{4}$ & 42 & 67 & 166 & 35 & 38 & 174 & 32 & 20 & 79 \\
\hline $\mathrm{C}_{2} \mathrm{H}_{6}$ & 267 & 253 & 486 & 241 & 198 & 228 & 190 & 178 & 150 \\
\hline $\mathrm{H}_{2}$ & 5819 & 3290 & 5803 & 6446 & 5159 & 4615 & 6602 & 5476 & 4992 \\
\hline co & 1868 & 1431 & 1574 & 1412 & 937 & 712 & 1355 & 1132 & 872 \\
\hline $\mathrm{CO}_{2}$ & 1021 & 543 & 787 & 640 & 266 & 112 & 801 & 259 & 154 \\
\hline
\end{tabular}


んど炭種に依存しない。この結果から，幅広い炭化度の石 炭をコークス用原料炭として利用しようとする場合, $360^{\circ} \mathrm{C}$ 程度の低温度域での熱分解挙動を把握することが極めて重 要であると結論づけられる。各保持温度で得られた $180 \mathrm{~min}$ 後の重量減少量と昇温熱分解実験で得られた重量減少量を 各々工業分析の揮発分で割った揮発分転化率をFig. 7 に示
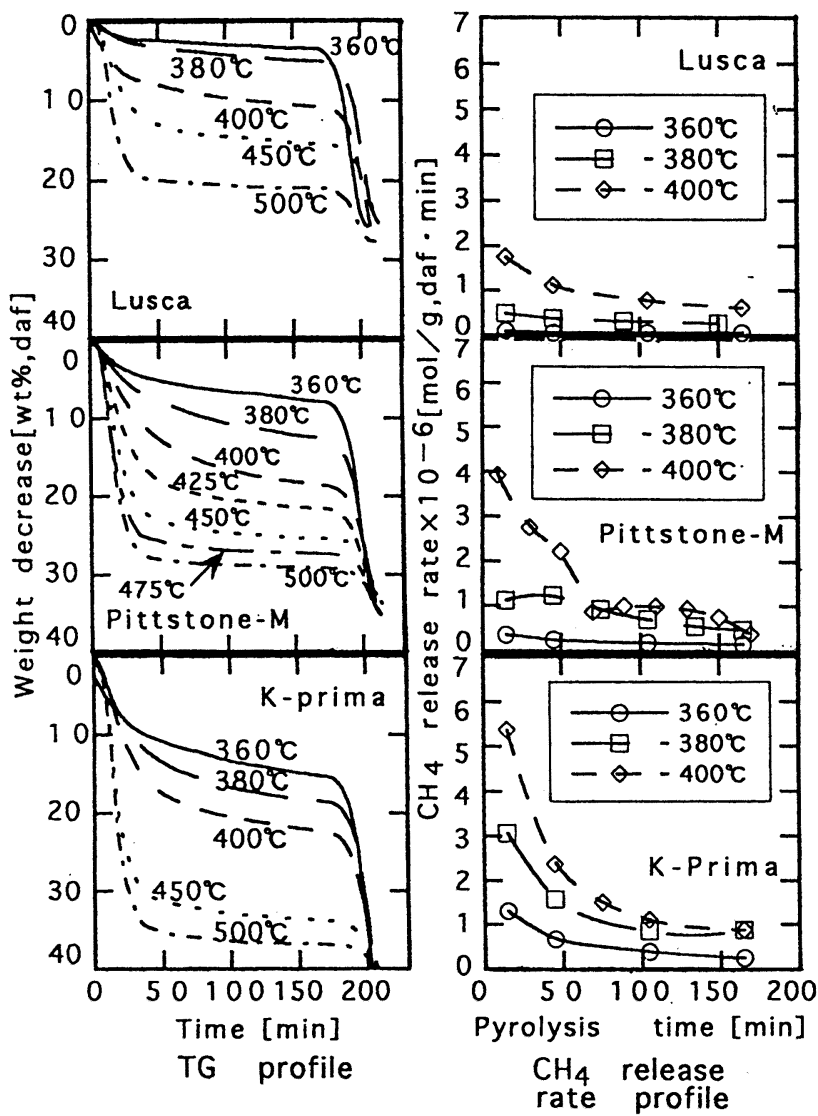

Fig. 5. TG profiles and gas release rate profiles at constant temperatures.
す。石炭はKp炭である。各保持温度での揮発分転化率は昇 温熱分解実験の結果を上回ることから， $3^{\circ} \mathrm{C} / \mathrm{min} の$ 低速昇 温でも熱分解速度が温度上昇に追随出来ないことが分かる。 この傾向は全ての石炭において認められた。

各保持温度で180minまでに発生したガス量をTable 3 に示

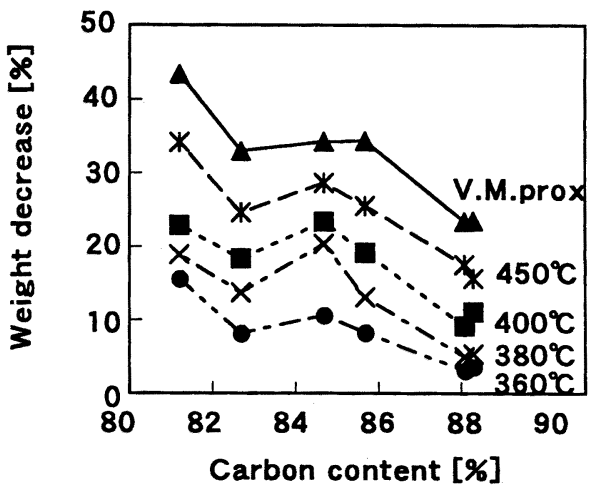

Fig. 6. Ultimate weight decrease at holding temperature vs. carbon content in raw coal.

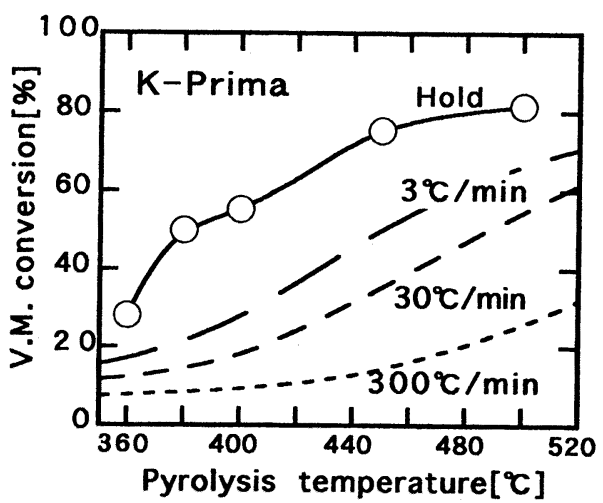

Fig. 7. Comparison of ultimate weight decrease at holding temperature with weight decrease in heating at constant rate.

Table 3. Amount of gas evolved until $180 \mathrm{~min}$ of heating time.

\begin{tabular}{|c|c|c|c|c|c|c|c|c|c|c|c|c|}
\hline \multirow{3}{*}{$\begin{array}{c}\text { gas } \\
\text { species }\end{array}$} & \multicolumn{12}{|c|}{ gas evolved $\left[\times 10^{-6} \mathrm{~mol} / \mathrm{g}\right.$ daf $]$} \\
\hline & \multicolumn{6}{|c|}{ Holding temp. : $360^{\circ} \mathrm{C}$} & \multicolumn{6}{|c|}{ Holding temp. : $380^{\circ} \mathrm{C}$} \\
\hline & Kp & Wi & Wo & $\mathbf{P i}$ & Go & Lu & Kp & $\mathbf{W i}$ & Wo & $\mathrm{Pi}$ & Go & Lu \\
\hline $\mathrm{CH}_{4}$ & 108 & 38 & 80 & 0 & 15 & 13 & 256 & 138 & 191 & 152 & 66 & 63 \\
\hline $\mathrm{C}_{2} \mathrm{H}_{4}$ & 6 & 6 & 1 & 5 & 1 & 0 & 17 & 7 & 10 & 8 & 2 & 3 \\
\hline $\mathrm{C}_{2} \mathrm{H}_{6}$ & 31 & 10 & 22 & 2 & 9 & 5 & 65 & 35 & 53 & 38 & 16 & 18 \\
\hline $\mathbf{H}_{2}$ & 0 & 0 & 0 & 0 & 0 & 0 & 0 & c & 0 & 0 & 0 & 0 \\
\hline CO & 44 & 23 & 2 & 4 & 2 & 12 & 99 & 49 & 39 & 46 & 18 & 18 \\
\hline $\mathrm{CO}_{2}$ & 242 & 175 & 16 & & 108 & 104 & 507 & 316 & 196 & 235 & 165 & 89 \\
\hline \multirow{3}{*}{$\begin{array}{c}\text { gas } \\
\text { species }\end{array}$} & \multicolumn{12}{|c|}{ gas evolved $\left[\times 10^{-8} \mathrm{~mol} / \mathrm{g}\right.$ daf $]$} \\
\hline & \multicolumn{6}{|c|}{ Holding temp. : $400^{\circ} \mathrm{C}$} & \multicolumn{6}{|c|}{ Holding temp. : $450^{\circ} \mathrm{C}$} \\
\hline & $\mathrm{Kp}$ & Wi & Wo & $\mathrm{Pi}$ & Go & Lu & Kp & Wi & Wo & $\mathbf{P i}$ & Go & Lu \\
\hline $\mathrm{CH}_{4}$ & 367 & 258 & 351 & 280 & 218 & 129 & 1053 & 915 & 1113 & 734 & 1140 & 1029 \\
\hline $\mathrm{C}_{2} \mathrm{H}_{4}$ & 24 & 15 & 24 & 20 & 9 & 6 & 89 & 39 & 54 & 46 & 48 & 39 \\
\hline $\mathrm{C}_{2} \mathrm{H}_{6}$ & 101 & 71 & 104 & 105 & 49 & 31 & 246 & 221 & 226 & 193 & 196 & 169 \\
\hline $\mathrm{H}_{2}$ & 0 & 0 & 0 & 0 & 0 & 0 & 49 & 101 & 106 & 45 & 44 & 100 \\
\hline CO & 183 & 53 & 97 & 77 & 36 & 27 & 354 & 127 & 149 & 90 & 68 & 77 \\
\hline $\mathrm{CO}_{2}$ & 785 & 262 & 381 & 341 & 189 & 138 & 869 & 319 & 552 & 379 & 265 & 227 \\
\hline
\end{tabular}




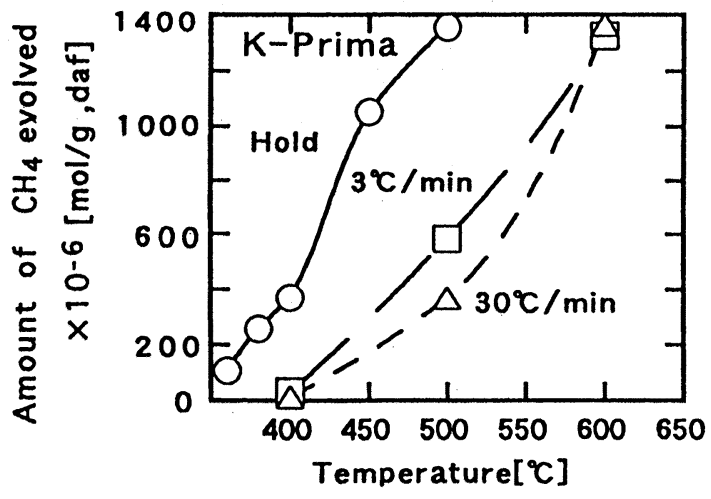

Fig. 8. Comparison of ultimate $\mathrm{CH}_{4}$ yield at holding temperature with $\mathrm{CH}_{4}$ yield in heating at constant rate.

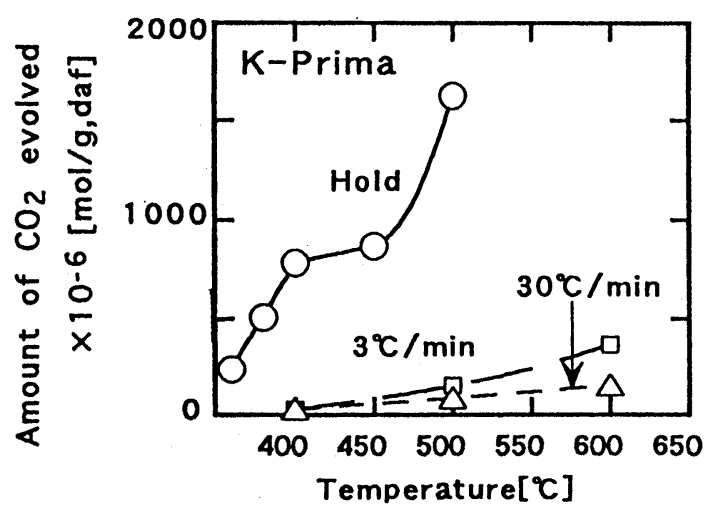

Fig. 9. Comparison of ultimate $\mathrm{CO}_{2}$ yield at holding temperature with $\mathrm{CO}_{2}$ yield in heating at constant rate.

す。重量減少の場合々同様にガス発生量は保持温度に強く 依存し, 一般的に低温度では $\mathrm{CO}_{2}$ 発生量が多く, 保持温度の 上昇とともに徐々に $\mathrm{CH}_{4}$ 発生量が増加する。また,この程度 の温度領域では熱分解時間を長くしても $\mathrm{H}_{2}$ 発生量は極めて 少ないことが認められた。昇温熱分解実験結果との比較を Fig. 8, Fig. 9 に示す。Fig. 8 は $\mathrm{CH}_{4}$ 発生量, Fig. 9 は $\mathrm{CO}_{2}$ 発生量の結果である。 $\mathrm{CH}_{4}, \mathrm{CO}_{2}$ 発生量とも温度を保持する ことによって低温度域での発生量が著しく増大寸ることが
分かる。この現象は全ての石炭で顕著に認められた。すな わち，この程度の低温度域では石炭の熱分解速度が極めて 遅いため, 加熱時間によってガスの総発生量が著しく異な る。従来の研究で行われていた昇温熱分解ではほとんぼ発 生が認められないような温度域でも，加熱時間が長くなれ ばかなりの量のガス発生が生ずることは注目に值する。ま た, 熱分解時の $\mathrm{CO}_{2}$ 生成は石炭中のカルボキシル基の分解 関係しているとの報告がある10,11)が, 本実験で使用したよう な高炭化度炭に含まれるカルボキシル基は極めてわずかで ある ${ }^{12)} こ と か ら, \mathrm{CO}_{2}$ 生成の機構に関しては更に検討が必要 と思われる。

\section{4. 結論}

炭素含有量の異なる 6 種の石炭を用いて熱分解時の重量 減少速度及びガス発生速度に対する昇温速度の影響を系統 的に検討し, 昇温速度の増加に伴い, 最大重量減少速度及 び最大ガス発生速度が高温側にシフトすること，コーク収 率及びガス収率が減少し液収率が増加することを明らかに した。また，360～ $500^{\circ} \mathrm{C}$ の低温度域で一定温度熱分解する ことにより各熱分解温度での究極揮発分量を決定し, 各温 度域での究極揮発分量の炭化度依存性は保持温度が低いほ に゙大きいことを見いだした。

\section{文献}

1) H.Juntgen and K.H.van Heek: Fuel, 47 (1968), 103.

2 ) D.W.van Krevelen : Coal, Elsevier Scientific Publishing Company, (1981), 266, 302.

3 ) D.Merrick: Fuel, 62 (1983), 534.

4 ) D.Kocaefe, A.Charette and L.Castonguay: Fuel, 74 (1995), 791.

5 ) J.B.Howard: Chemistry of Coal Utilization, ed. by M.A. Elliott, John Wiley \& Sons, (1981), 719

6 ) R.J.Tyler: Fuel, 58 (1979), 680.

7 ) W.R.Ladner: Fuel Processing Technology, 20 (1988), 207.

8 ) W.-C.Xu and A.Tomita : Fuel, 66 (1987), 632.

9 ) 小島紀徳, 松方正彦, 南雲篤郎：コークス・サーキュラー, 41 (1992), 224.

10) W.-C.Xu and A.Tomita: Fuel, 66 (1987), 627.

11) Harry N.S.Schafer: Fuel, 58 (1979), 673.

12）木村英雄，藤井修治：石炭化学 $\varepsilon 工$ 業，三共出版，(1983)，96. 